\title{
Modeling evidence that ozone depletion has impacted extreme precipitation in the austral summer
}

\author{
S. M. Kang, ${ }^{1}$ L. M. Polvani, ${ }^{2,3}$ J. C. Fyfe, ${ }^{4}$ S.-W. Son, ${ }^{5}$ M. Sigmond, ${ }^{4}$ and G. J. P. Correa ${ }^{3}$ \\ Received 15 June 2013; revised 15 July 2013; accepted 16 July 2013; published 8 August 2013.
}

[1] The impacts of stratospheric ozone depletion on the extremes of daily precipitation in the austral summer are explored using two global climate models. Both models indicate that stratospheric ozone losses since the late 1970s may have increased the frequency and intensity of very heavy precipitation in austral summer over southern high and subtropical latitudes, and may have decreased the frequency and intensity over southern midlatitudes. This hemispheric wide pattern of extreme precipitation response projects strongly onto a previously identified pattern of seasonal mean precipitation response, both of which are shown to be likely of dynamic rather than thermodynamic origin. Citation: Kang, S. M., L. M. Polvani, J. C. Fyfe, S.-W. Son, M. Sigmond, and G. J. P. Correa (2013), Modeling evidence that ozone depletion has impacted extreme precipitation in the austral summer, Geophys. Res. Lett., 40, 4054-4059, doi:10.1002/grl.50769.

\section{Introduction}

[2] Over recent decades, the middle- to high-latitude Southern Hemisphere ( $\mathrm{SH}$ ) circulation in the austral summer has changed markedly, as characterized by a trend toward the high-index polarity of the $\mathrm{SH}$ annular mode (SAM) [Thompson et al., 2000; Marshall, 2003; Fogt et al., 2009]. The positive SAM trend reflects a poleward shift of the southern extratropical jet and the accompanying storm tracks [Archer and Caldeira, 2008] and a poleward shift of the edge of the Hadley circulation [Hu and Fu, 2007]. Related to these changes in circulation is a pattern of midlatitude drying and high-latitude moistening that has been attributed to anthropogenic greenhouse gas and ozone changes, with an opposing influence from aerosols [Fyfe et al., 2012]. Additionally, ozone changes are shown to have affected rainfall in the southern subtropics, resulting in enhanced precipitation over large parts of the Indian Ocean, Australia, and over

\footnotetext{
${ }^{1}$ School of Urban and Environmental Engineering, Ulsan National Institute of Science and Technology, Ulsan, South Korea.

${ }^{2}$ Department of Applied Physics \& Applied Mathematics, and Department of Earth \& Environmental Sciences, Columbia University, New York, New York, USA.

${ }^{3}$ Lamont-Doherty Earth Observatory, Columbia University, Palisades, New York, USA.

${ }^{4}$ Canadian Centre for Climate Modelling and Analysis, Environment Canada, Victoria, British Columbia, Canada.

${ }^{5}$ School of Earth and Environmental Sciences, Seoul National University, Seoul, South Korea.

Corresponding author: S. M. Kang, School of Urban and Environmental Engineering, Ulsan National Institute of Science and Technology, UNIST-gil50, Ulsan, 689-798 South Korea. (skang@unist.ac.kr)

(C)2013. American Geophysical Union. All Rights Reserved. 0094-8276/13/10.1002/grl.50769
}

the southern flank of the Southern Pacific Convergence Zone [Kang et al., 2011].

[3] Although much progress has been made with detection and attribution of seasonal mean climate changes, extreme rainfall changes over the $\mathrm{SH}$ extratropics to our best knowledge have not yet been investigated, possibly due to limited data availability. Recent analysis on global extreme precipitation changes in the twentieth century only covers land area [Sillmann et al., 2013; Donat et al., 2013], so that it is hard to infer changes over the mostly oceancovered SH. Hence, in this paper, we extend the study of Kang et al. [2011] to include an assessment of the consequences of stratospheric ozone depletion on the extremes of daily precipitation in the $\mathrm{SH}$, recognizing that changes in the frequency and intensity of very heavy precipitation, for example, may have had a more direct and immediate societal impact than the long-term changes in seasonal mean rainfall. These ozone hole-induced changes are expected to be relevant to the observed changes because the recent changes in the SH circulation and rainfall in austral summer are largely forced by stratospheric ozone depletion [Karpechko et al., 2008; Polvani et al., 2011; McLandress et al., 2011; Kang et al., 2011]. No observational analysis is included in this study due to data limitations and low confidence in reanalysis products.

[4] In response to increasing greenhouse gases in the future, extreme precipitation is predicted to become more intense and frequent on the global scale [Sun et al., 2007; Kharin et al., 2007; Gastineau and Soden, 2009] and it has been suggested that these changes are more significantly thermodynamic in origin (i.e., involving moisture content changes) than dynamic in origin (i.e., involving atmospheric motion changes) [Emori and Brown, 2005; Gastineau and Soden, 2009; O'Gorman and Schneider, 2009]. However, for the recent $\mathrm{SH}$ climate changes in austral summer, dynamic changes have been shown to drive seasonal mean precipitation change, and thus our expectation is that dynamics rather than thermodynamics will control ozone holeinduced changes in extreme precipitation - if indeed such changes in extreme precipitation are found in the first place. In the study by Purich and Son [2012] where the models that contributed to Phase 3 of the Coupled Model Intercomparison Project (CMIP3) were divided into a group with ozone changes and a group without ozone changes, no systematic difference in extreme precipitation trends is found between the two groups. Even though this suggests that ozone changes are not associated with extreme precipitation trends, it remains to be firmly established if this is indeed the case. The comparison between the two CMIP3 groups is not well controlled, and the effects of ozone changes may have been masked by other forcings which might differ greatly among the models and were poorly documented (notably aerosol 


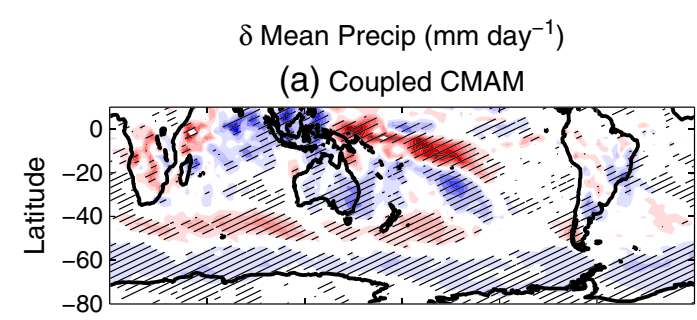

(b) Uncoupled CMAM

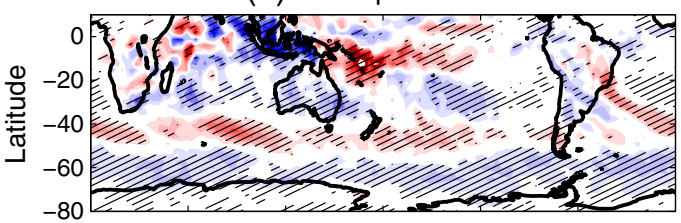

(c) Uncoupled CAM3
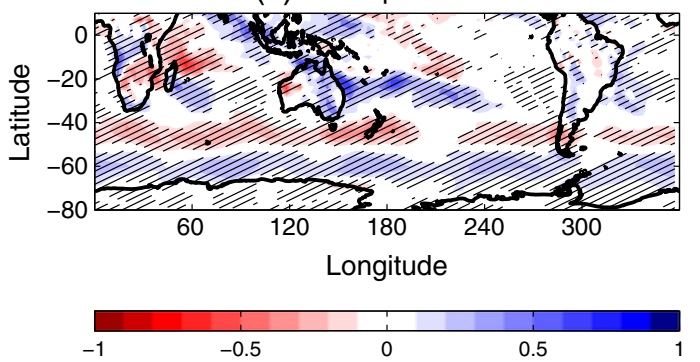

$\delta$ Very heavy precip $\left(\mathrm{mm}^{\mathrm{day}}{ }^{-1}\right)$

(d) Coupled CMAM

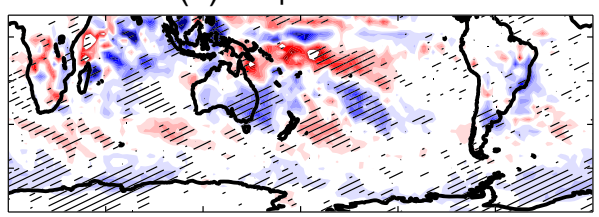

(e) Uncoupled CMAM

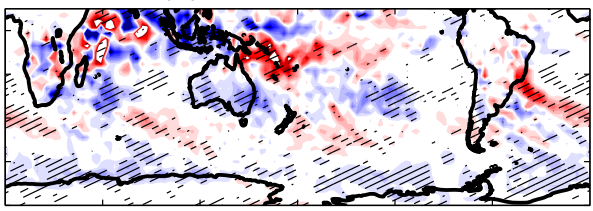

(f) Uncoupled CAM3
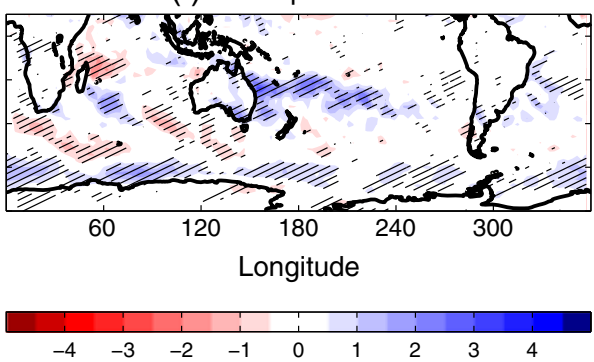

Figure 1. Changes due to ozone hole of (left) mean precipitation and (right) 99th percentile daily precipitation in (a, d) coupled CMAM, (b, e) uncoupled CMAM, and (c, f) uncoupled CAM3 in DJF. Units are in mm day ${ }^{-1}$. Locations where the response is significant at the 95\% confidence level following Welch's $t$ test are hatched.
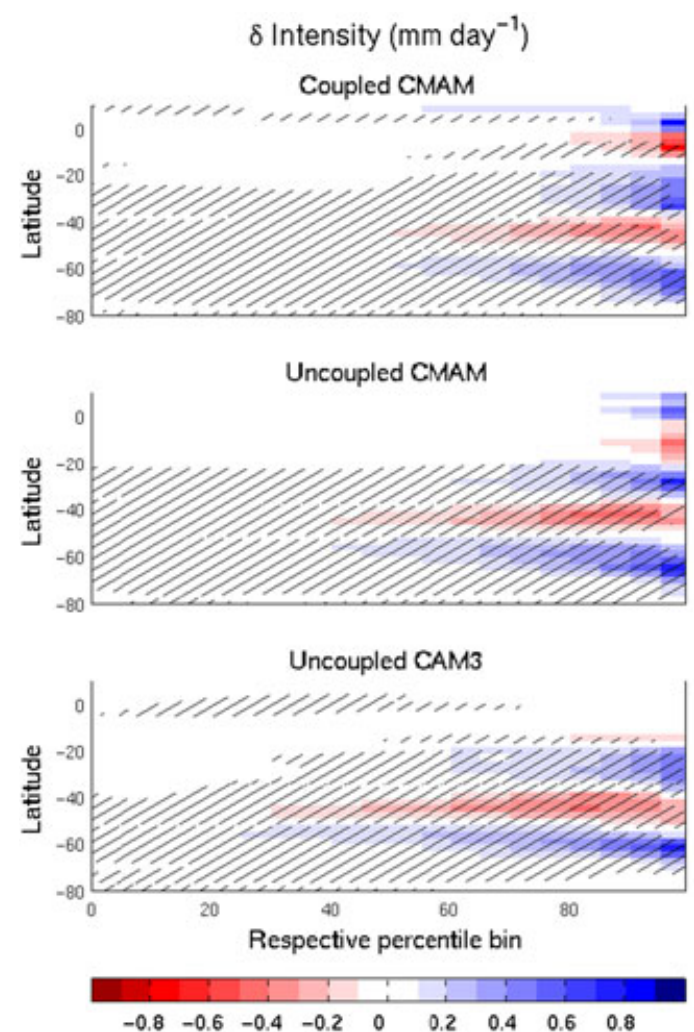
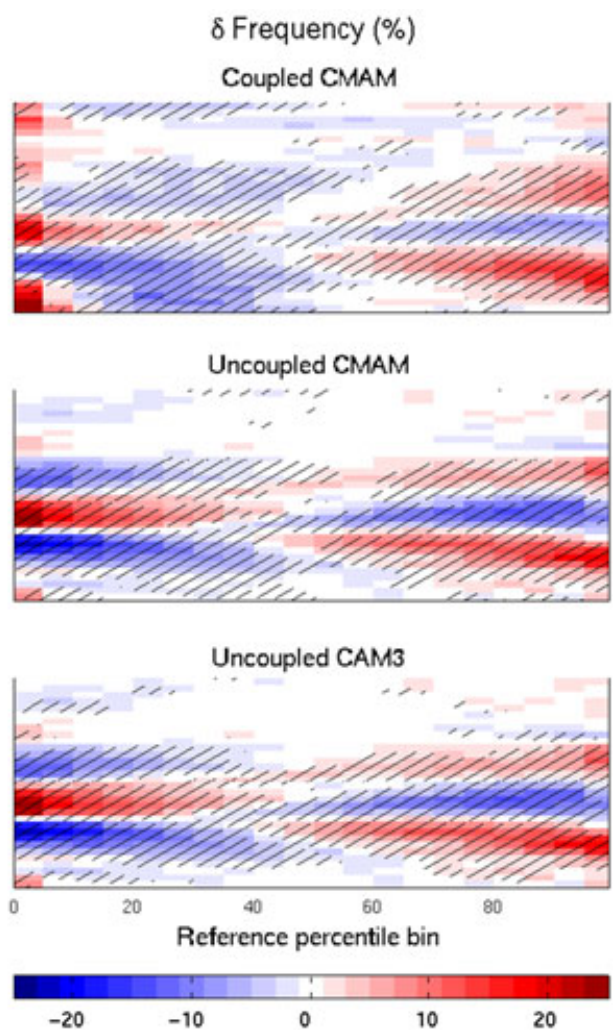

Figure 2. (Left) Zonal-mean changes in the intensity of precipitation ( $\mathrm{mm} \mathrm{day}^{-1}$ ) and (right) zonal-mean percentage changes in the frequency of occurrence of precipitation (\%) in (upper) coupled CMAM, (middle) uncoupled CMAM, and (lower) uncoupled CAM3. Locations where the response is significant at the 95\% confidence level following Welch's $t$ test are hatched. 

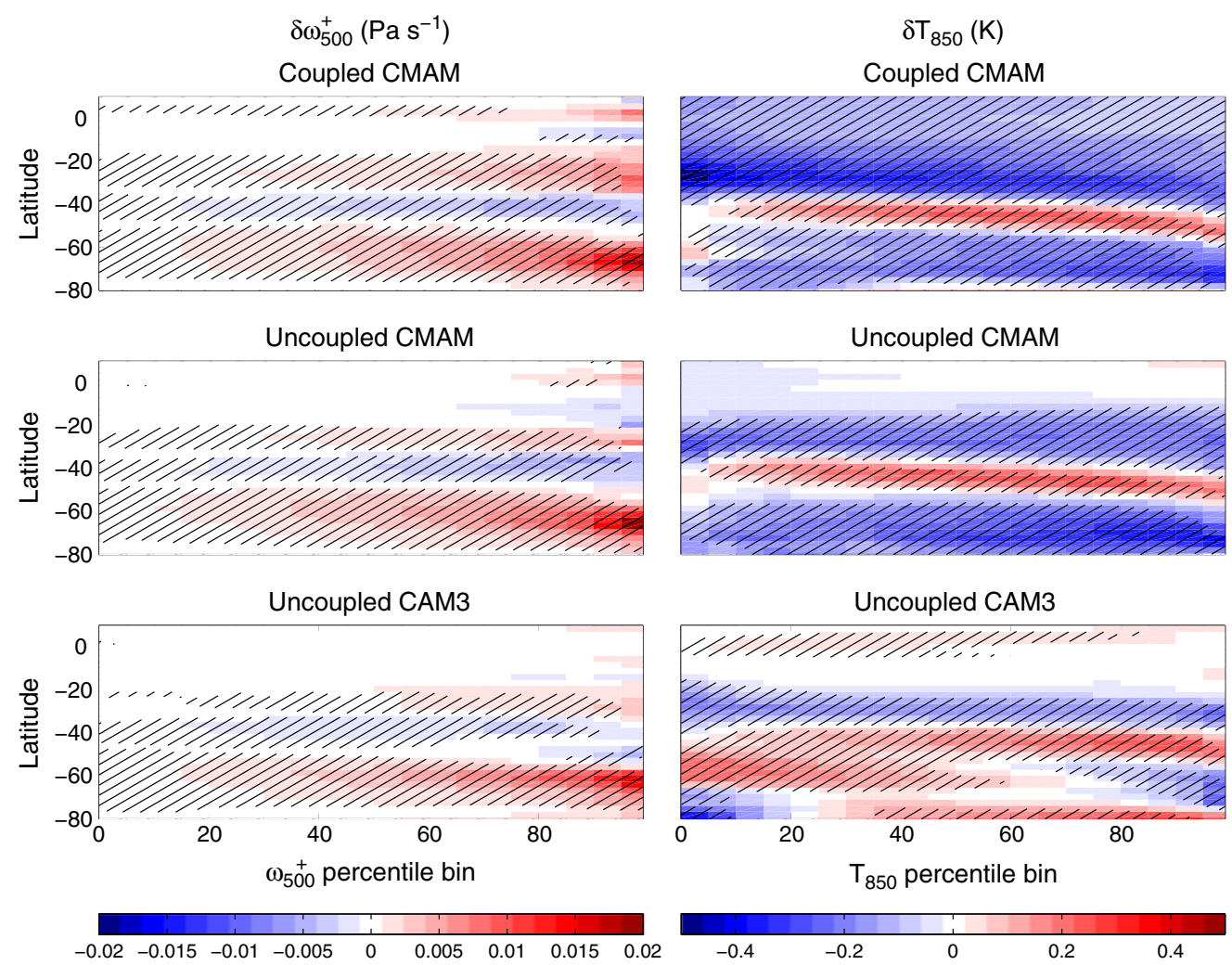

Figure 3. Zonal-mean changes in the intensity of (left) ascending pressure velocity at $500 \mathrm{hPa}\left(\omega_{500}^{+}\right.$in $\left.\mathrm{Pa} \mathrm{s} \mathrm{s}^{-1}\right)$ and (right) temperature at $850 \mathrm{hPa}\left(T_{850}\right.$ in $\mathrm{K}$ ) in (upper) coupled CMAM, (middle) uncoupled CMAM, and (lower) uncoupled CAM3. Locations where the response is significant at the $95 \%$ confidence level following Welch's $t$ test are hatched.

direct and indirect effects). To circumvent these problems, our study focuses on a carefully conceived set of multimodel integrations forced only with observed stratospheric ozone changes. This single-forcing approach allows us to show robust changes in daily precipitation, particularly in their extremes, in response to stratospheric ozone depletionand that these changes are likely of a dynamic rather than thermodynamic nature.

\section{Data and Methods}

[5] We employ two independent climate models that are very different in their physical parameterizations. One is the Canadian Middle Atmosphere Model (CMAM) [Scinocca et al., 2008] and the other the National Center for Atmospheric Research Community Atmospheric Model (CAM3) [Collins et al., 2006]. Both models are integrated in a socalled "time-slice" manner, with prescribed monthly varying zonally symmetric latitude-height ozone fields, representative of the change in ozone from preozone-hole times (i.e., referred to as a "reference" integration) to the period when the ozone hole reached its record size (i.e., referred to as an "ozone hole" integration). Specifically, in CMAM, the climatological ozone fields in the reference integration are perturbed with the observed change between 1979 and 2005 in the ozone hole integration, whereas in CAM3 ozone concentrations are fixed to year 1960 in the reference integration and to year 2000 in the ozone hole integration. The climate response to stratospheric ozone depletion is obtained by subtracting the climatologies of the ozone hole and reference integrations and is denoted by $\delta$.

[6] CMAM is run with T63 horizontal resolution and 71 vertical levels from the surface to around $100 \mathrm{~km}$. The model is either coupled to an ocean, with a horizontal resolution of approximately $1.41^{\circ} \times 0.94^{\circ}$ and 40 vertical levels, together with a dynamic and thermodynamic sea ice model, or forced with prescribed sea surface temperatures and sea ice concentrations obtained from the coupled reference integration [Sigmond et al., 2010]. CAM3 is run with T42 horizontal resolution and 26 vertical levels from the surface to around $2.2 \mathrm{hPa}$. The sea surface temperatures and sea ice concentrations are prescribed from observations [Rayner et al., 2003], averaged from 1952 to 1968. Daily data for 80 years are analyzed for CMAM and 100 years for CAM3. These model integrations are identical to those used in Kang et al. [2011].

[7] Our analysis is focused on austral summer (i.e., December, January, and February; DJF) daily precipitation $(P)$, temperature at $850 \mathrm{hPa}\left(T_{850}\right)$, and ascending vertical pressure velocity at $500 \mathrm{hPa}\left(\omega_{500}^{+}\right)$. First, we compute the 5 th, 10th, ... 95th, and 99th percentiles of the daily data at each grid point for each of these variables. Then, the change in intensity is obtained, by differencing the average intensity within each percentile bin between the reference and ozone hole integrations. The change in frequency of occurrence is obtained following Gastineau and Soden [2009], by binning the variables using the percentile thresholds defined from the reference integration. Hence, the change in frequency 

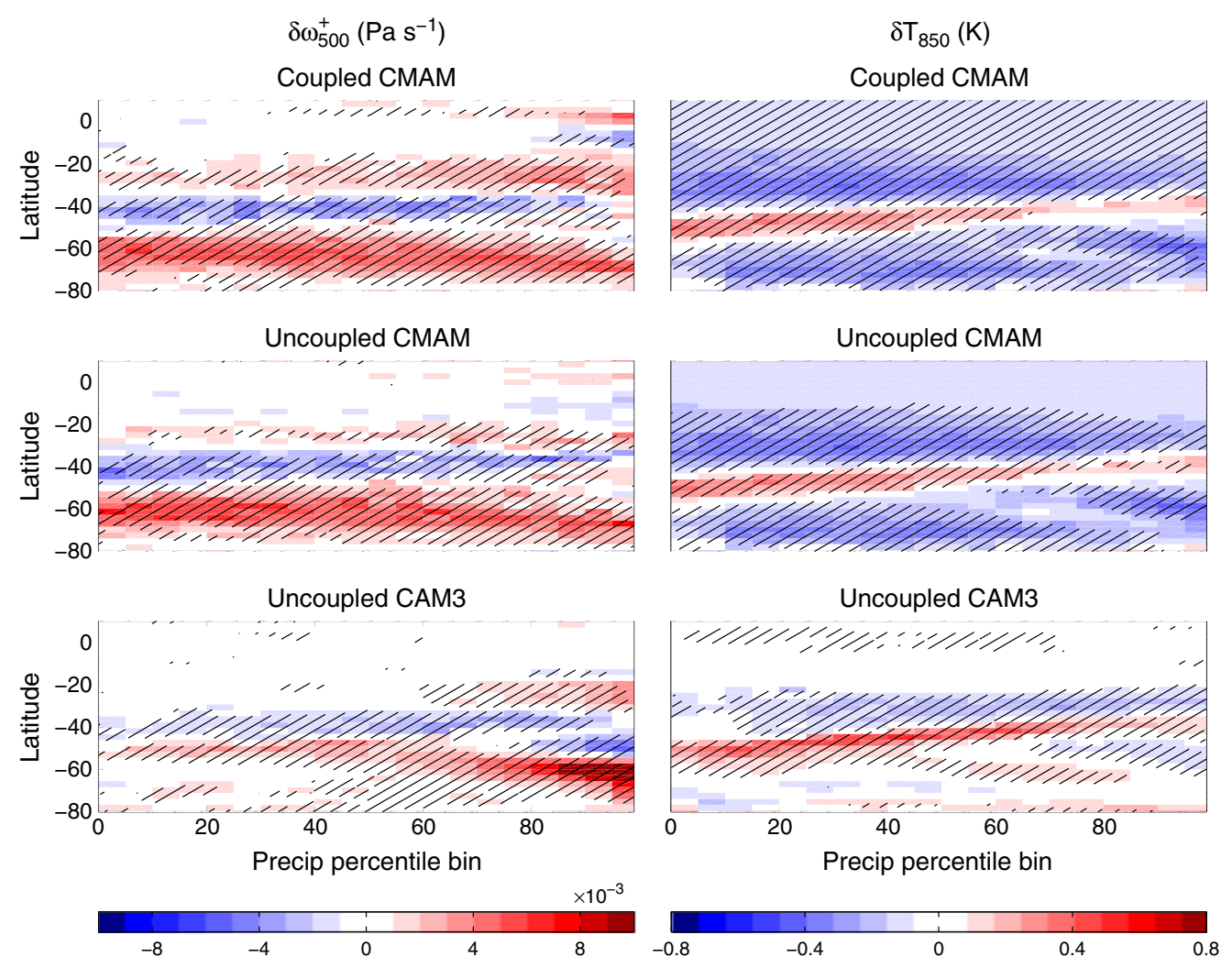

Figure 4. Zonal-mean changes in the intensity of (left) ascending pressure velocity at $500 \mathrm{hPa}\left(\omega_{500}^{+}\right.$in $\left.\mathrm{Pa} \mathrm{s}{ }^{-1}\right)$ and (right) temperature at $850 \mathrm{hPa}\left(T_{850}\right.$ in $\left.\mathrm{K}\right)$, averaged as a function of the corresponding precipitation percentile bins in (upper) coupled CMAM, (middle) uncoupled CMAM, and (lower) uncoupled CAM3. Locations where the response is significant at the $95 \%$ confidence level following Welch's $t$ test are hatched.

of occurrence is plotted relative to the reference percentile bins, whereas the change in intensity is plotted relative to the respective percentile bins.

\section{Results}

[8] Patterns of DJF mean precipitation response due to stratospheric ozone depletion are shown in Figure 1 on the left. In all model configurations, stratospheric ozone depletion results in high-latitude and subtropical moistening and midlatitude drying, as reported in Kang et al. [2011]. These ozone depletion-induced responses are qualitatively similar to the Southern Annular Mode (SAM)-related precipitation anomalies, seen both in observations and in models [Gillett et al., 2006; Previdi and Liepert, 2007]. In particular, the enhancement in mean precipitation over southeastern Australia is consistent with the precipitation anomalies normally associated with high values of the SAM index in DJF [Hendon et al., 2007]. Similarly, the dipolar extratropical precipitation response to ozone forcing is consistent with the poleward displacement of the westerly jet or equivalently with a positive trend in the SAM index [Son et al., 2009; Polvani et al., 2011; McLandress et al., 2011]. In addition to this midlatitude response, it is important to note the presence of an ozone depletion-induced subtropical moistening, associated with the poleward shift of the descending branch of the Hadley cell, as shown by Kang et al. [2011]. The right column of Figure 1 shows the pattern of 99th percentile precipitation response; note the scale difference between the left and right columns. The 99th percentile bin average will hereafter be referred to as "very heavy" precipitation. Qualitatively, Figure 1 shows that the pattern of very heavy precipitation response is similar to the pattern of mean precipitation response. The number of daily temperature extremes has been also shown to have a strong relationship with the seasonal mean over the New Hampshire land [Hamilton et al., 2012].

[9] Figure 2 shows the pattern of zonal-mean changes in the intensity and percent frequency of daily precipitation across all precipitation categories. The responses shown here are highly robust, in that they appear in all model configurations, and are statistically significant at the $95 \%$ confidence level at all latitudes poleward of about $20^{\circ} \mathrm{S}$. These changes in intensity and frequency, taken together, indicate that stratospheric ozone depletion shifts the distribution of daily precipitation toward heavy precipitation at latitudes experiencing mean moistening (e.g., over high and subtropical latitudes) and toward light precipitation at latitudes where mean drying is seen (e.g., over the midlatitudes).

[10] To examine the possible mechanisms of ozone depletion-induced change in extreme precipitation, we show in Figure 3 the latitudinal distribution of change in the intensity of the $500 \mathrm{hPa}$ ascending velocity $\left(\omega_{500}^{+}\right)$on the left and $850 \mathrm{hPa}$ temperature $\left(T_{850}\right)$ on the right, for all percentile bins. The dynamic effect is represented by $\delta \omega_{500}^{+}$and the thermodynamic effect by $\delta T_{850}$. Since the atmospheric moisture content is not fully independent of circulation, we refer to the thermodynamic effect as the response associated with 
local temperature changes. The changes in $\omega_{500}^{+}$intensity are highly correlated with the changes in precipitation $(P)$ intensity seen earlier in Figure 2 (left), with extrema in either case generally situated in the most intense categories. To be specific, the pattern correlation coefficient between the $\omega_{500}^{+}$and $P$ patterns of intensity response in Figures 2 (left) and 3 range from 0.58 for the uncoupled CAM 3 to 0.75 for coupled CMAM. On the other hand, the pattern of intensity response for $T_{850}$ does not show a distinctive peak at either end of the spectrum and is only weakly negatively correlated with the responses of $P$ and $\omega_{500}^{+}$intensity (by about -0.2 regardless of a model). Moreover, the $T_{850}$ intensity responses poleward of $50^{\circ} \mathrm{S}$ are not robust across the models (with cooling in CMAM for all percentile bins, warming in CAM3 for weak-to-moderate percentile bins from $50^{\circ} \mathrm{S}-70^{\circ} \mathrm{S}$, and for moderate-to-strong percentile bins poleward of $70^{\circ} \mathrm{S}$ ) - whereas the $P$ and $\omega_{500}^{+}$intensity responses are highly robust at all latitudes. Here we note that the positive $T_{850}$ intensity responses in the band of latitudes centered near $45^{\circ} \mathrm{S}$ coincides with the descending branch of anomalous meridional circulation shown in Figures $4 \mathrm{C}$ and $4 \mathrm{~F}$ in Kang et al. [2011], as is indicative of adiabatic warming [Thompson and Wallace, 2000].

[11] To compare more directly the dynamic and thermodynamic effects on precipitation intensity responses, we next bin $\omega_{500}^{+}$and $T_{850}$ as functions of precipitation intensity. More specifically, $\omega_{500}^{+}$and $T_{850}$ for the reference and ozone hole integrations are averaged over the corresponding $P$ percentile bins and the differences shown in Figure 4. The responses in $\omega_{500}^{+}$conditioned on $P$ intensity are concentrated in the weak $P$ intensity regime, which is in contrast to the $P$ intensity responses which themselves are concentrated in the heavy precipitation regime (see Figure 2 (left)). Since $\omega_{500}^{+}$controls large-scale condensation, less coherence between the patterns of response shown in Figures 2 and 4 suggests the involvement of small-scale convection and may also explain the lack of robustness of the patterns of $\delta \omega_{500}^{+}$ intensity between the models. The $T_{850}$ intensity responses conditioned on $P$ intensity bear little resemblance to the $P$ intensity responses themselves, i.e., the magnitude of $\delta T_{850}$ intensity decreases with $P$, whereas that of $\delta P$ increases with $P$, and the signs of $\delta T_{850}$ intensity and $\delta P$ intensity are largely opposite. This indicates that the response of extreme daily precipitation to stratospheric ozone depletion is very likely dynamic rather than thermodynamic in origin.

\section{Discussion}

[12] The impact of the Antarctic ozone hole on the extremes of austral summer daily precipitation has been investigated using two global climate models. Due to limited data availability in the $\mathrm{SH}$, it is hard to robustly determine observed changes in extreme precipitation, but we believe that ozone hole-induced changes that are reported here may be relevant to the observed changes because seasonal mean changes are well explained by the model integrations forced by the ozone hole [Kang et al., 2011] and that ozone forcing is the main driver of recent $\mathrm{SH}$ atmospheric circulation changes [Polvani et al., 2011; McLandress et al., 2011].

[13] The ozone hole is found to drive a distinct geographical pattern of extreme precipitation response where responses in the intensity of very heavy precipitation, for example, coincide with regions of seasonal mean moistening or drying. To compare the relative role of dynamics and thermodynamics in driving the extreme precipitation responses that our models simulate, we analyzed the responses in ascending velocity at $500 \mathrm{hPa}\left(\omega_{500}^{+}\right)$and $850 \mathrm{hPa}$ temperature $\left(T_{850}\right)$. In this way, we found that responses in intensity of precipitation across all categories are well correlated with intensity responses of $\omega_{500}^{+}$across all model configurations. This is in contrast to the pattern of $T_{850}$ response that was found not to be related to the pattern of precipitation response-suggesting that ozone-induced changes in extreme daily precipitation are likely dynamical rather than thermodynamical in origin.

[14] Acknowledgments. We thank two anonymous reviewers for their constructive comments that helped greatly to improve earlier version of the manuscript. S.M. Kang is supported by the 2013 Creativity \& Innovation Research Fund 1.130033 of UNIST (Ulsan National Institute of Science and Technology).

[15] The Editor thanks two anonymous reviewers for their assistance evaluating this manuscript.

\section{References}

Archer, C. L., and K. Caldeira (2008), Historical trends in the jet streams, Geophys. Res. Lett., 35, L08803, doi:10.1029/2008GL033614.

Collins, W. D., et al. (2006), The Formulation and Atmospheric Simulation of the Community Atmosphere Model Version 3 (CAM3), J. Clim., 19(11), 2144-2161.

Donat, M. G., et al. (2013), Updated analyses of temperature and precipitation extreme indices since the beginning of the twentieth century: The HadEX2 dataset, J. Geophys. Res. Atmos., 118, 2098-2118., doi:10.1002/jgrd.50150.

Emori, S., and S. J. Brown (2005), Dynamic and thermodynamic changes in mean and extreme precipitation under changed climate, Geophys. Res. Lett., 32, L17706, doi:10.1029/2005GL023272.

Fogt, R. L., J. Perlwitz, A. Monaghan, D. Bromwich, J. Jones, and G. Marshall (2009), Historical SAM variability. Part II: Twentieth-century variability and trends from reconstructions, observations, and the IPCC AR4 models, J. Clim., 22, 5346-5365.

Fyfe, J. C., N. P. Gillett, and G. J. Marshall (2012), Human influence on extratropical Southern Hemisphere summer precipitation, Geophys. Res. Lett, 39, L23711, doi:10.1029/2012GL054199.

Gastineau, G., and B. J. Soden (2009), Model projected changes of extreme wind events in response to global warming, Geophys. Res. Lett., 36 , L10810, doi:10.1029/2009GL037500.

Gillett, N. P., T. D. Kell, and P. D. Jones (2006), Regional climate impacts of the Southern Annular Mode, Geophys. Res. Lett., 33, L23704, doi:10.1029/2006GL027721.

Hamilton, E., R. Eade, R. J. Graham, A. A. Scaife, D. M. Smith, A Maidens, and C. MacLachlan (2012), Forecasting the number of extreme daily events on seasonal timescales, J. Geophys. Res., 117, D03114, doi:10.1029/2011JD016541.

Hendon, H. H., D. W. J. Thompson, and M. C. Wheeler (2007), Australian rainfall and surface temperature variations associated with the Southern Hemisphere Annular Mode, J. Clim., 20(11), 2452-2467.

$\mathrm{Hu}$, Y., and Q. Fu (2007), Observed poleward expansion of the Hadley circulation since 1979, Atmos. Chem. Phys., 7, 5229-5236.

Kang, S. M., L. M. Polvani, J. C. Fyfe, and M. Sigmond (2011), Impact of polar ozone depletion on subtropical precipitation, Science, 332(6032), 951-954.

Karpechko, A. Y., N. P. Gillett, G. J. Marshall, and A. A. Scaife (2008), Stratospheric influence on circulation changes in the Southern Hemisphere troposphere in coupled climate models, Geophys. Res. Lett., 35 , L20806, doi:10.1029/2008GL035354.

Kharin, V. V., F. W. Zwiers, X. Zhang, and G. C. Hegerl (2007), Changes in temperature and precipitation extremes in the IPCC ensemble of global coupled model simulations, J. Clim., 20(8), 1419-1444.

Marshall, G. (2003), Trends in the Southern Annular Mode from observations and reanalyses, J. Clim., 16, 4134-4143.

McLandress, C., T. G. Shepherd, J. F. Scinocca, D. A. Plummer, M. Sigmond, A. I. Jonsson, and M. C. Reader (2011), Separating the dynamical effects of climate change and ozone depletion. Part II: Southern Hemisphere troposphere, J. Clim., 24(6), 1850-1868.

O'Gorman, P. A., and T. Schneider (2009), The physical basis for increases in precipitation extremes in simulations of 21 st-century climate 
change, Proc. Natl. Acad. Sci, 106(35), 14,773-14,777, doi:10.1073/ pnas.0907610106.

Polvani, L. M., D. W. Waugh, G. J. P. Correa, and S.-W. Son (2011), Stratospheric ozone depletion: The main driver of twentieth-century atmospheric circulation changes in the Southern Hemisphere, J. Clim., 24(3), 795-812.

Previdi, M., and B. G. Liepert (2007), Annular modes and Hadley cell expansion under global warming, Geophys. Res. Lett., 34, L22701, doi:10.1029/2007GL031243.

Purich, A., and S.-W. Son (2012), Impact of Antarctic ozone depletion and recovery on Southern Hemisphere precipitation, evaporation, and extreme changes, J. Clim., 25(9), 3145-3154.

Rayner, N. A., D. E. Parker, E. B. Horton, C. K. Folland, L. V. Alexander, D. P. Rowell, E. C. Kent, and A. Kaplan (2003), Global analyses of sea surface temperature, sea ice, and night marine air temperature since the late nineteenth century, J. Geophys. Res., 108(D14), doi:10.1029/2002JD002670

Scinocca, J. F., N. A. McFarlane, M. Lazare, J. Li, and D. Plummer (2008), Technical Note: The CCCma third generation AGCM and its extension into the middle atmosphere, Atmos. Chem. Phys., 8(23), 7055-7074, doi:10.5194/acp-8-7055-2008.

Sigmond, M., J. C. Fyfe, and J. F. Scinocca (2010), Does the ocean impact the atmospheric response to stratospheric ozone depletion?, Geophys. Res. Lett., 37, L12706, doi:10.1029/2010GL043773.

Sillmann, J., V. V. Kharin, X. Zhang, F. W. Zwiers, and D. Bronaugh (2013), Climate extremes indices in the CMIP5 multimodel ensemble: Part 1. Model evaluation in the present climate, J. Geophys. Res. Atmos., 118, 1716-1733, doi:10.1002/jgrd.50203.

Son, S.-W., N. F. Tandon, L. M. Polvani, and D. W. Waugh (2009), Ozone hole and Southern Hemisphere climate change, Geophys. Res. Lett., 36, L15705, doi:10.1029/2009GL038671.

Sun, Y., S. Solomon, A. Dai, and R. W. Portmann (2007), How often will it rain?, J. Clim., 20(19), 4801-4818.

Thompson, D. W. J., and J. M. Wallace (2000), Annular modes in the extratropical circulation. Part I: Month-to-month variability, J. Clim., 13(5), 1000-1016.

Thompson, D. W. J., J. M. Wallace, and G. C. Hegerl (2000), Annular modes in the extratropical circulation. Part II: Trends, J. Clim., 13, 1018-1036. 